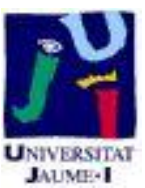

Título artículo / Títol article: Large scale synthesis of nanostructured zirconiabased compounds from freeze-dried precursors.

Autores / Autors

Gómez, Andrés ; Villanueva, Regina ; Vie, D. ;

Murcia Mascaros, S. ; Martínez, E. ; Beltrán, Aurelio

; Sapiña, Fernando ; Vicent, Mónica ; Sánchez

Vilches, Enrique Javier

Revista:

Journal of Solid State Chemistry

Versión / Versió: $\quad$ Pre-print

Cita bibliográfica / Cita

GÓMEZ, A., et al. Large scale synthesis of bibliogràfica (ISO 690): nanostructured zirconia-based compounds from freeze-dried precursors. Journal of Solid State Chemistry, 2013, vol. 197, p. 120-127.

url Repositori UJI:

http://hdl.handle.net/10234/96773 


\title{
Large scale synthesis of nanostructured zirconia-based compounds from freeze-dried precursors
}

\author{
A.Gómez ${ }^{\text {a }}$, R.Villanueva ${ }^{\text {a }}$, D.Vie ${ }^{\text {a }}$, S.Murcia-Mascaros a ${ }^{\text {, E.Martínez }}{ }^{\text {a }}$ A.Beltrán ${ }^{\text {a }}$, F. Sapiña a ${ }^{\text {a* }}$, \\ M. Vicent ${ }^{\text {b }}$, E. Sánchez ${ }^{\text {b }}$ \\ a Institut de Ciència dels Materials, Parc Cientific, Universitat de València, PO Box 22085, 46071 Valencia, Spain \\ b Instituto de Tecnología Cerámica - Asociación de Investigación de las Industrias Cerámicas \\ Universitat Jaume I, 12006 Castellón, Spain
}

Corresponding author: Tel.: +34 9635436 26; fax: +34 963543633 .

E-mail address: fernando.sapina@uv.es (F. Sapiña) 


\begin{abstract}
Nanocrystalline zirconia powders have been obtained at the multigram scale by thermal decomposition of precursors resulting from the freeze-drying of aqueous acetic solutions. This technique has equally made possible to synthesize a variety of nanostructured yttria or scandia doped zirconia compositions. SEM images, as well as the analysis of the XRD patterns, show the nanoparticulated character of those solids obtained at low temperature, with typical particle size in the $10-15 \mathrm{~nm}$ range when prepared at $673 \mathrm{~K}$. The presence of the monoclinic, the tetragonal or both phases depends on the temperature of the thermal treatment, the doping concentration and the nature of the dopant. In addition, Rietveld refinement of the XRD profiles of selected samples allows detecting the coexistence of the tetragonal and the cubic phases for high doping concentration and high thermal treatment temperatures. Raman experiments suggest the presence of both phases also at relatively low treatment temperatures.
\end{abstract}

Keywords: Powders-chemical preparation; Freeze-drying; Microstructure-final; Grain size; $\mathrm{ZrO}_{2}$ 


\section{Introduction}

Nanostructured materials have been profusely investigated in the last three decades [1, 2], not only for the scientific interest in understanding relations among certain fundamental properties of solids and their particle size and morphology [3], but also for many technological applications [4]. Nanostructured materials are solids usually consisting of aggregates of ultrafine particles (mostly crystallites of 1-100 $\mathrm{nm}$ in at least one direction). They have a high proportion of atoms at the particle and/or grain (crystallite) boundaries (compared to their conventional bulk microcrystalline equivalents), what many times results in novel properties of interest. Insofar as a primary unavoidable question is how to make up nanostructured materials, chemists are playing an important role in the progress of nanoscience and nanotechnology [5]. Some time ago, it was appropriately noted that a relevant part of the legacy of research on high temperature superconductors was the redrawing of the frontiers of synthetic (and structural) solid state chemistry [6], with the development of a diversity of procedures and techniques to reach low temperature synthesis of complex systems as one of the key contributions in this field [7].

At present, a great number of processes for the preparation of nanostructured powders has been described [3, 5, 7-9]. However, most of these methods are expensive, require sophisticated equipment and yield relatively low production rates. Therefore, they have high production costs and are conceived for obtaining high value-added materials, with typical applications in the fields of electronics and photonics. In general, the problems (both procedural and economics) become severe when relatively large scale (multigram, around a few hundred grams) preparative processes (technically feasible) are required [10, 11]. In this context, "powder processing methods for the preparation of submicrometer and nanostructured powders in a controlled form, with a wide range of compositions, sizes, and morphologies, need to be improved" [12]. In practice, our group has widely reported on the competitive advantages of the freeze-drying method [13-15] for obtaining a diversity of nanostructured materials (oxides, nitrides, carbides, intermetallics) as polycrystalline powders with controlled characteristics (composition and particle morphology) [12, 16-18].

Research on zirconia-based compounds, which are among the most widely studied ceramic materials [19], is still growing as more applications for these materials arise in very different fields, from advanced ceramics to biomaterials [20-24]. It must be noted, however, that mechanical properties 
(fundamental in diverse applications) of pure bulk zirconia at high temperatures are poor due to the martensitic phase change from the monoclinic to the tetragonal form [25]. Nevertheless, the introduction of different divalent or trivalent cations ('stabilizers') in place of zirconium stabilizes the tetragonal and the cubic forms versus the monoclinic one [26]. These zirconia-based materials show very good mechanical and thermal properties, being extremely resistant to thermal shock. In addition, they exhibit considerable ionic conductivity at elevated temperatures, due to the migration of oxygen vacancies induced by the stabilizer [27]. In any case, concerning the influence of the microstructural characteristics on the behavioral features, there are abundant evidences of the advantages of using nanostructured zirconia-based materials in applications such as solid oxide fuel cells (SOFCs) or thermal barrier coatings (TBCs) [28-32].

In the present work, we report on the use of freeze-dried precursors for the preparation of zirconia nanoparticles. In addition, the substitution of yttrium and scandium for zirconium has also been explored. A few related approaches have been presented in recent years dealing with dispersed zirconia nanoparticles [10], but these elegant processes might be difficult to implement with multimetallic systems for production in the industry. The use of the freeze-drying synthetic approach has allowed us the preparation of different nanostructured zirconia-based materials at the $100 \mathrm{~g}$ scale making use of simple equipment utilized for a long time in different productive sectors. In practice, thinking on industrial application, a first seemingly obvious requirement is to have at our disposal low-cost simple synthetic strategies allowing to produce multigram amounts of the adequate nanostructured starting powder.

\section{Materials and methods}

\subsection{Synthesis}

2.1.1. Materials: The materials used as reagents in the current investigation were zirconium acetate, $\mathrm{Zr}\left(\mathrm{CH}_{3} \mathrm{COO}\right)_{4}$ (Aldrich, solution in dilute acetic acid, 15-16\% $\mathrm{Zr}$ ), yttrium oxide, $\mathrm{Y}_{2} \mathrm{O}_{3}$ (Aldrich 99.99\%), scandium oxide, $\mathrm{Sc}_{2} \mathrm{O}_{3}$ (Aldrich, 99.9\%), glacial acetic acid (Panreac, 99.5\%), ethanol (Scharlau, 99.9\%), and nitric acid (Panreac, 65\%).

2.1.2. Preparation of precursors at the laboratory scale: $\mathrm{Y}_{2} \mathrm{O}_{3}$ was dissolved under reflux in a solution of acetic acid:ethanol:nitric acid 5: 1: 0.02 (v: v: v). $\mathrm{Sc}_{2} \mathrm{O}_{3}$ was dissolved under reflux in a 
solution of acetic acid:water:nitric acid 5: 1.5: 0.15 (v: v: v). By combining these solutions with the zirconium acetate reagent solution, we obtained $\mathrm{Zr}-\mathrm{Y}$ or $\mathrm{Zr}-\mathrm{Sc}$ source solutions whose total cationic concentration was $0.60 \mathrm{M}$, with molar nominal compositions $\mathrm{Zr}: \mathrm{Y}$ or $\mathrm{Zr}: \mathrm{Sc}=1-\mathrm{x}: \mathrm{x}$ (x = 0, 0.03, 0.06, $0.09,0.12)$. The amounts of the different reagents were adjusted to give $5 \mathrm{~g}$ of the final $\left(\mathrm{Zr}_{1-\mathrm{x}} \mathrm{A}_{\mathrm{x}}\right) \mathrm{O}_{2-\mathrm{x} / 2}(\mathrm{~A}$ $=\mathrm{Y}, \mathrm{Sc}$ ) oxides (what implies the freeze-drying of $c a .68 \mathrm{~mL}$ of the source solutions). Droplets of these solutions were flash frozen by projection on liquid nitrogen and, then, freeze-dried at a pressure of $10^{-4}$ atm in a Telstar Cryodos freeze drier. In this way, dried solid precursors were obtained as amorphous (Xray diffraction) loose powders. The thermal evolution of the precursors was monitored by thermogravimetric experiments (TGA-DTA) under oxygen atmosphere (heating rate $5 \mathrm{~K} \mathrm{~min}^{-1}$, flow rate $50 \mathrm{~cm}^{3} \mathrm{~min}^{-1}$ ), using a Setaram Setsys 16/18 System. In all cases, decomposition of the precursors yielding oxides is complete at $623 \mathrm{~K}$.

2.1.3. Synthesis of nanostructured oxides at the laboratory scale: The different samples were synthesized by heating the amorphous freeze-dried precursor under air atmosphere. The precursors (ca. $0.5 \mathrm{~g}$ ) were placed into an alumina crucible of $c a .5 \mathrm{~cm}^{2}$ of usable surface, and introduced in the tubular furnace. Several runs under different experimental conditions were performed in order to determine their influence in the structure and microstructure of the resulting solids. The precursor powders were heated at $5 \mathrm{~K} \mathrm{~min}^{-1}$ to a final temperature $\mathrm{T}_{\mathrm{f}}\left(\mathrm{T}_{\mathrm{f}}=573\right.$ to $1573 \mathrm{~K}$, in steps of $\left.100 \mathrm{~K}\right)$ that was held for a period of time $\left(t_{\text {hold }}\right)$ of $6 \mathrm{~h}$ under air atmosphere. The solids were then cooled down by turning off the oven leaving the sample inside (slow cooling, ca. $2 \mathrm{~K} \mathrm{~min}^{-1}$ ). All products were stored in a desiccator over silica gel. In line with the TGA-DTA observations, in these conditions, oxides formation is detected at $673 \mathrm{~K}$ (see below).

2.1.4. Synthesis scale-up: The freeze-drying technique allowed obtaining large quantities of the precursors. In the case we are dealing with, a Telstar Cryodos freeze drier works with up to $c a$. $1.5 \mathrm{~L}$ of source solutions. Such a volume is adequate for the production of $c a .110 \mathrm{~g}$ of the final oxide in a single batch. We obtained even higher oxide quantities ( $c a .220 \mathrm{~g}$ ) by using a Telstar Lyoalpha freeze drier, which allows processing up to $c a .3 \mathrm{~L}$ of source solutions. In both cases, some selected zirconia doped samples were prepared by thermal decomposition of the precursors at $673 \mathrm{~K}\left(\mathrm{t}_{\text {hold }}=6 \mathrm{~h}\right)$ in a muffle furnace under circulating oxygen, which guarantees an oxidizing atmosphere and forces the exit of the combustion gases. In all cases, the precursors were placed into alumina rectangular dishes $\left(c a .100 \mathrm{~cm}^{2}\right)$ 
that were placed at different levels in the muffle furnace. The products were cooled at $c a .2 \mathrm{~K} \mathrm{~min}^{-1}$, and stored in a desiccator over silica gel. The solids so obtained are indistinguishable (XRD, SEM) from their counterparts obtained at the laboratory scale.

\subsection{Characterization}

2.2.1. X-ray diffraction: X-ray powder diffraction (XRD) patterns were obtained from a diffractometer (Brucker AXS-5005) using $\mathrm{Cu}-\mathrm{K}_{\alpha}$ radiation. Samples were dusted through a sieve on the holder surface. Routine patterns were collected with a scanning step of $0.08^{\circ}$ between $20-70^{\circ}$ in $2 \theta$ with a collection time of 5 s per step. Patterns for microstructural analysis and profile fitting were collected with a scanning step of $0.02^{\circ}$ between $20-110^{\circ}$ in $2 \theta$ with a collection time of $10 \mathrm{~s}$ per step. Profile fittings were performed using the FULLPROF program [33].

2.2.2. Microstructural characterization: The morphology of both the freeze dried precursors and the resulting oxides was observed using a scanning electron microscope-field emission (Hitachi 4100FE) operating at an accelerating voltage of $30 \mathrm{kV}$. All the preparations were covered with a thin film of gold for better image definition.

2.2.3. Surface areas: The BET surface areas of the products were determined by nitrogen adsorption (Micromeritics ASAP 2000) at $77 \mathrm{~K}$ assuming a cross-sectional area of $0.162 \mathrm{~nm}^{2}$ for the nitrogen molecule. Prior to adsorption measurements, the samples were degassed in vacuum at $423 \mathrm{~K}$ for $18 \mathrm{~h}$.

2.2.4. Agglomerate sizes: The agglomerate size distributions corresponding to $\mathrm{Y}$ containing samples $(\mathrm{x}=0.06)$ prepared at 773 and $973 \mathrm{~K}$ were determined by dynamic light scattering (Zetasizer Nano ZS). An ultrasonic probe (UP400S) was used to break down soft aggregates before determining the size distributions. Optimal results were obtained using diluted suspensions $\left(0.1 \mathrm{~g} \mathrm{~L}^{-1}\right)$, citric acid as dispersant $(0.2 \%)$ and 3 min of sonication time.

2.2.5. Raman spectroscopy: Micro-Raman spectroscopy was carried out at room temperature, in a backscattering configuration and using the $532 \mathrm{~nm}$ line from a fibre coupled single-wavelength solid state laser for excitation. The scattered light was dispersed by a Jobin Yvon iHR320 spectrometer and detected with a Peltier-cooled CCD. The typical system spectral resolution was around $2 \mathrm{~cm}^{-1}$. The laser beam was focused on the sample's surface using a Chylas S.L. fibre optic compact probe with 20x 
objective. In order to prevent from local heating and transformation, laser power varied from 1 to $54 \mathrm{~mW}$. Recording times ranged from 30 to 120 seconds, with 5 to 100 accumulation scans depending on the sample. Measurements were carried out directly on the sample with no previous preparation of any kind.

\section{Results and discussion}

The thermal evolution of the precursors was monitored by means of TGA analysis and X-ray powder diffractometry. As mentioned in the experimental section, the TGA curves show that, in all cases, decomposition of the precursors yielding oxides is complete at $623 \mathrm{~K}$. Figure 1 shows the XRD patterns of the powders resulting from the thermal treatment of the precursor samples at temperatures ranging from 673 to $1473 \mathrm{~K}$, in $200 \mathrm{~K}$ intervals. Dealing with pure zirconia (Figure 1a), the only crystalline product observed at $673 \mathrm{~K}$ is the tetragonal modification of $\mathrm{ZrO}_{2}$, whereas the monoclinic one is the only detected phase at temperatures above $1473 \mathrm{~K}$. In the 773 to $1373 \mathrm{~K}$ range, the diffraction patterns correspond to mixtures of the tetragonal and the monoclinic modifications of $\mathrm{ZrO}_{2}$, the phase transformation continuously progressing with temperature (as indicated by the evolution of the relative intensities of the diffraction peaks). The introduction of $\mathrm{Y}$ results in changes in the temperature values delimiting the stability field of each phase. Indeed, both the temperature at which the monoclinic phase begins to be detected (tetragonal/two phases limit) and that from which the tetragonal phase is no longer present (two phases/monoclinic limit) are now significantly higher than in the pure zirconia case. Thus, for $x=0.06$ (Figure 1b), the diffraction patterns of the samples prepared at temperatures up to $1273 \mathrm{~K}$ correspond to the tetragonal modification. Above $1273 \mathrm{~K}$, the XRD patterns indicate the presence of mixtures of the tetragonal and the monoclinic modifications, the relative intensities of the peaks of the monoclinic polymorph increasing with temperature. For high doping concentrations, $x=0.12$, the tetragonal form is the only crystalline phase detected along the entire temperature range studied (673$1573 \mathrm{~K}$ ). A similar behaviour is observed when zirconia is doped with Sc, although the temperature limit values are not as greatly affected as in the $\mathrm{Y}$ case. Thus, for $\mathrm{x}=0.06$ (Figure 1c), the tetragonal modification remains as the only crystalline phase up to $873 \mathrm{~K}$. At $1473 \mathrm{~K}$, the monoclinic phase is clearly dominant (with only a very small contribution to the pattern of the tetragonal one, in contrast to the $\mathrm{Y}$ case). 
Summarized in Table 1 are the grain (crystallite) sizes corresponding to samples of pure zirconia and $6 \% \mathrm{Y}$ or Sc stabilized zirconia prepared at different temperatures. The crystallite size values have been estimated using the Debye-Scherrer equation by analysis of the $(101)_{t}$ and $(-111)_{m}$ peaks [34]. LaB 6 has been used as standard for the correction of the instrumental contribution to the width of the peaks. The crystallite sizes remain around $10-15 \mathrm{~nm}$ for samples prepared at relatively low temperatures (up to ca. $973 \mathrm{~K}$ ), and increase with temperature. At the highest temperature reached in this work, $1573 \mathrm{~K}$, crystallite sizes around 40-60 nm are obtained. Otherwise, these results are similar to those obtained for all the compositions studied in each series.

Shown in Figure 2 are characteristic SEM images corresponding to representative samples of pure zirconia and $6 \% \mathrm{Y}$ or Sc stabilized zirconia prepared at different temperatures. The average particle size values have been estimated from measurements (using an image treatment software) of $c a .50$ different particles. In all cases, the samples prepared at $973 \mathrm{~K}$ are constituted by aggregates of rounded particles with typical sizes varying in the $26-57 \mathrm{~nm}$ range depending on the composition (see Table 1). Particle sizes progressively increase with temperature. Indeed, the mean particle size in samples prepared at $1173 \mathrm{~K}$ rises up to $c a .61-86 \mathrm{~nm}$, whereas it clearly exceeds the nanometric scale $(c a .200-368 \mathrm{~nm})$ at $1573 \mathrm{~K}$ (Table 1). Besides such a particle size increase, we can observe also a morphological evolution from rounded particles to polyhedral faceted ones. In any case, taking into account that crystallite sizes (XRD) are significantly smaller than particle sizes (SEM), it points out the polycrystalline character of the particles even in the case of samples prepared at relatively low temperatures. An additional observation that deserves to be highlighted is the comparatively small particle size in the case of $Y$ containing samples with regard to analogous pure zirconia or Sc doped samples.

Summarized in Table 1 are also the surface area values as experimentally determined $\left(S_{\exp }\right)$ from the $\mathrm{N}_{2}$ adsorption-desorption isotherms (BET model) together with the corresponding approximated values calculated $\left(\mathrm{S}_{\text {calc }}\right)$ from SEM particle sizes (assuming pseudo-spherical particles). As can be observed, the really accessible surface areas are appreciably lower than those expected from SEM observations, what indicates that particles are significantly agglomerated in the powder samples. Interestingly, the BET areas of $\mathrm{Y}$ containing samples (Table 1) are notably lower than those corresponding to analogous pure zirconia or Sc doped samples. Bearing in mind the above observation on the particle size trends, this result clearly suggests that the agglomeration degree produced in the $\mathrm{Y}$ 
containing samples is remarkably high. Indeed, the agglomerate size distribution corresponding to Y containing samples $(\mathrm{x}=0.06)$ prepared at 773 and $973 \mathrm{~K}$ (determined by dynamic light scattering) is, in both cases, bimodal. Thus, a large proportion of the agglomerates has a mean particle size of $530 / 560 \mathrm{~nm}$ (773/973 K), whereas a comparatively low proportion of the agglomerates exhibit mean particle sizes of $120 \mathrm{~nm}$ in both cases.

In this context, an interesting experimental observation concerns the consequences of the particle size on the crystalline form adopted. Thus, it is well known that microparticulated zirconia crystallizes in the monoclinic form, while nanoparticulated zirconia (particles lesser than $c a .30 \mathrm{~nm}$ ) does it in the tetragonal form (although it has also been claimed that very low sized nanoparticles, $c a$. 2 nm, would stabilize the cubic phase) $[35,36]$. Obviously, this particle-size driven structural transition is not a $\mathrm{ZrO}_{2}$ exclusive situation [37]. It has been frequently concluded that microparticulated samples of these oxides adopt the thermodynamically stable structural variety, whereas those shown by nanoparticulated ones are metastable [38]. However, there is abundant information in the literature supporting the idea that effects of the particle sizes on the surface energies of the polymorphs can explain adequately (on a thermodynamic basis) the stability crossover for surface areas above a certain critical value [38, 39]. Indeed, according to the experimental results of the group of Navrotsky, the surface energy of monoclinic and the tetragonal forms of $\mathrm{ZrO}_{2}$ are 4.2 and $0.9 \mathrm{~J} \mathrm{~m}^{-2}$, respectively [39]. This would imply, in practice, that surface energy differences can thermodynamically stabilize nanoparticulated tetragonal $\mathrm{ZrO}_{2}$ over nanoparticulated monoclinic $\mathrm{ZrO}_{2}$.

On the other hand, it is well known the 'stabilizing' effect of partial substitution of Sc or Y for $\mathrm{Zr}$ in conventional (microparticulated) zirconia: the free energy difference between the tetragonal and the monoclinic forms decreases with doping, and the tetragonal phase becomes the more stable one above a critical concentration of the 'stabilizer' cation. Nanoparticulated materials behave in a similar way. This notwithstanding, the influence of the surface enthalpies on the relative stability of the two polymorphs involves a certain complexity. Indeed, Figure 3 schematically summarizes our experimental results in terms of the fraction of the monoclinic phase obtained at a given temperature (for different doping concentrations). These results reflect the fact that, both for $\mathrm{Y}$ and $\mathrm{Sc}$ containing zirconia, the temperature values delimiting the tetragonal/two-phases and the two-phases/monoclinic transitions increase with substitution ( $\mathrm{x}$ value). In practice, above a given doping level, the tetragonal form becomes the more 
stable one along the entire range of temperatures studied in this work. Such a limiting value is $\mathrm{x}=0.12$ $(12 \%)$ in the Y case, and slightly higher in the Sc case.

We have tried to go more deeply into the structural behaviour of these compounds by means of profile fittings of selected XRD patterns acquired at room temperature. Summarized in Tables 2-5 are the main structural data obtained for the entire series of $\left(\mathrm{Zr}_{1-\mathrm{x}} \mathrm{A}_{\mathrm{x}}\right) \mathrm{O}_{2-\mathrm{x} / 2}$ samples prepared at $973 \mathrm{~K}$ (relatively low temperature) and $1573 \mathrm{~K}$. The fits were performed using a pseudo-Voigt peak-shape function. In the final runs, the usual profile parameters (scale factors, background coefficients, zero-points, half-width, pseudo-Voigt and asymmetry parameters for the peak-shape) and atomic positions were refined. Isotropic thermal parameters were set at 0.5 and $0.9 \AA^{2}$ for metal and oxygen atoms, respectively, and an overall thermal parameter was also refined. In the structural models, $\mathrm{Zr}, \mathrm{Y}$ and $\mathrm{Sc}$, as well as oxygen vacancies induced by doping, are considered to be randomly distributed in the cationic and anionic sites, and their occupancies were fixed according to the nominal metal stoichiometry and oxygen content.

As a matter of fact, at first, all the recorded patterns can be rather accurately indexed by considering the presence of the monoclinic (space group P $2_{1} / \mathrm{c}$ ) and the tetragonal $\left(\mathrm{P} 44_{2} / \mathrm{nmc}\right.$ ) zirconialike structures, either as isolated phases or as a mixture of both of them. This is so even for high dopant concentration $(x \geq 0.09)$, where the patterns can be initially indexed with the tetragonal phase. Nevertheless, in some cases $\left(\mathrm{T}_{\mathrm{f}}=1573 \mathrm{~K}\right)$, the final refinements are unsatisfactory, as the difference plots (residual intensities) indicate (Figure 4a). A more detailed inspection of these last profiles shows the presence of a low intensity multiplet, centred at $74^{\circ} 2 \theta$ (Figure $4 \mathrm{~b}$ ), which was not considered in the initial indexation. According to the literature data [40], this multiplet should be indicative of the presence of the cubic zirconia-like phase $(\mathrm{Fm}-3 \mathrm{~m})$ together with the tetragonal one. Hence, a reconsideration of the refinements allowing for mixtures of the $\mathrm{P} 4_{2} / \mathrm{nmc}$ and $\mathrm{Fm}-3 \mathrm{~m}$ phases leads to more satisfactory adjustments (Figures $4 \mathrm{~b}$ and $4 \mathrm{c}$ ). Although we only have clearly detected the presence of the cubic zirconia-like phase in the case of samples $(\mathrm{A}=\mathrm{Y}, \mathrm{x}=0.09,0.12 ; \mathrm{A}=\mathrm{Sc}, \mathrm{x}=0.12)$ prepared at a high temperature $\left(\mathrm{T}_{\mathrm{f}}=1573 \mathrm{~K}\right)$, the apparent absence of the revealing multiplet in the patterns of the corresponding samples prepared at relatively low temperature $(973 \mathrm{~K})$ might be due to experimental limitations: the closeness of these weak diffraction peaks, together with their expected comparatively larger widths (due to size effect), might mask the presence of the cubic phase. In fact, once confirmed its presence in the case of the $1573 \mathrm{~K}$ samples, and taking into account previous observations concerning the 
influence of the crystallite size in the cubic to tetragonal transformation in the $\mathrm{Zr}$-containing oxide nanoparticles [41], what seems likely is the presence of the cubic phase in the samples prepared at $973 \mathrm{~K}$.

Raman spectroscopy provides us additional evidences on this point because it is sensitive to oxygen displacement in the cubic phase. Indeed, the Raman spectra of Y-doped samples $(x=0.12)$ prepared at 973 and $1573 \mathrm{~K}$ look very similar (Figure 5a), and clearly show four bands centered at 257 , 316, 464 and $634 \mathrm{~cm}^{-1}$. Moreover, they display a broad shoulder (centered at ca.700 $\mathrm{cm}^{-1}$ ). The main difference between them refers to the presence of some very weak effects (at around 350 to $450 \mathrm{~cm}^{-1}$ ) in the case of the $1573 \mathrm{~K}$ sample.

In the case of nanometric tetragonal zirconia (space group $\mathrm{P} 4_{2} / \mathrm{nmc}$ ), we expect six vibrational Raman active modes, with symmetries $\mathrm{A}_{1 \mathrm{~g}}+2 \mathrm{~B}_{1 \mathrm{~g}}+3 \mathrm{E}_{\mathrm{g}}$ and located at 150, 260, 320, 480, 602 and $650 \mathrm{~cm}^{-}$ ${ }^{1}$.[42] In contrast, in the cubic fluorite-type structure (space group Fm-3m), only one vibrational Raman $\mathrm{T}_{2 \mathrm{~g}}$ active mode is expected at around $605 \mathrm{~cm}^{-1}$.[43] Therefore, in the case of the spectrum of the Y-doped $1573 \mathrm{~K}$ sample (whose XRD unambiguously confirms the presence of the cubic phase), taking into account to the literature data [43], we can reasonably assign the bands centered at 257, 316 and $464 \mathrm{~cm}^{-1}$, to the tetragonal Raman vibrational modes of symmetries $E_{g}, B_{1 g}$ and $E_{g}$, whereas the structured band at $634 \mathrm{~cm}^{-1}$ must have contributions of the $\mathrm{A}_{1 \mathrm{~g}}$ and $\mathrm{E}_{\mathrm{g}}$ tetragonal and $\mathrm{T}_{2 \mathrm{~g}}$ cubic Raman vibrational modes. Otherwise, the close correspondence between the main features of the spectra of both the $973 \mathrm{~K}$ and the $1573 \mathrm{~K}$ samples, strongly suggests the presence of a mixture of the tetragonal and the cubic phases also in the case of the $973 \mathrm{~K}$ sample. In fact, the deconvolution of the baseline corrected profiles in the 500-750 $\mathrm{cm}^{-1}$ region (Figures $5 \mathrm{~b}$ and $5 \mathrm{c}$ ) supports the assumption of the presence of a mixture of the tetragonal and the cubic phases. Thus, the profiles have been resolved into four peaks (centered at 605/ 607, 626/ 630, $638 / 640$, and $\left.721 / 706 \mathrm{~cm}^{-1}\right)$ in both cases $(973 / 1573 \mathrm{~K})$. The $605 / 607 \mathrm{~cm}^{-1}$ peak is assigned to the cubic phase and the peaks at $626 / 630$ and $638 / 640 \mathrm{~cm}^{-1}$ to the tetragonal phase. The $721 / 706 \mathrm{~cm}^{-1}$ peak, which accounts for the above mentioned shoulder at around $700 \mathrm{~cm}^{-1}$ in the spectra, is attributable to a defect induced band [44]. Finally, the very weak bands $\left(350-450 \mathrm{~cm}^{-1}\right)$ in the spectrum of the $1573 \mathrm{~K}$ sample (seemingly "lost" in the wider-bands spectrum of the $973 \mathrm{~K}$ sample because of their weakness) must be due to fluorescence of rare-earth impurities at very low concentrations [45].

In any case, by comparing analogous $\mathrm{Y}$ and Sc series, the observed trends in both the nature of the structures and the evolution of the cell parameters with increasing substitution, can be understood on 
the basis of the disorder introduced by the presence of anionic vacancies, together with the variation of the mean value of the cationic radius. Indeed, disorder increases with the substitution degree, what facilitates the transition from more ordered (lower symmetry, $\mathrm{P} 22_{1} / \mathrm{c}$ ) structures to more disordered (higher symmetry $\mathrm{P} 4_{2} / \mathrm{nmc}, \mathrm{F} \mathrm{m}-3 \mathrm{~m}$ ) structures. This tendency is enhanced in the $\mathrm{Y}$ case, whose cationic radius is significantly higher than that of $\mathrm{Sc}$ and $\mathrm{Zr}$ (for coordination number 8: $\mathrm{Zr}(\mathrm{IV}), 84 \mathrm{pm}$; $\mathrm{Sc}(\mathrm{III}), 87$ pm; Y(III), $102 \mathrm{pm})$. So, in the Y case, the monoclinic to tetragonal transition occurs for lower doping levels (minor $\mathrm{x}$ ). With regard to the evolution of the cell parameters, we can also observe how the monoclinic or tetragonal distortion decrease as the substitution degree increases, a variation which is modulated by the differences in cationic radii (Tables 2-5).

\section{Conclusions}

In summary, nanoparticulated zirconia and both Y and Sc-doped zirconia can be successfully prepared by thermal decomposition at relatively low temperatures of precursors obtained by freeze-drying of appropriate solutions. This technique has been easily implemented at the $100 \mathrm{~g}$ scale. The desired stabilization of the tetragonal versus the monoclinic form is dependent on the concentration and size of the dopant as well as on the temperature of the thermal treatment. On the other hand, for high dopant concentration, a mixture of the tetragonal and the cubic forms is inferred from XRD and Raman experiments. Once controlled the synthetic approach, we are investigating the use of these materials in applications in which the agglomeration of the final powder is not relevant (because of the very nature of the processing), such as the preparation of nanostructured coatings using atmospheric plasma spraying (APS) [46-48].

\section{Acknowledgements}

This study has been supported by the Spanish Ministry of Science and Technology and EU FEDER Program (MAT2006-12945-C0-01, MAT2006-12945-C0-03, MAT2009-14144-C03-01, MAT2009-14144-C03-03). The SCSIE of the Universitat de València is gratefully thanked for the use of the X-ray diffraction, electron microscopy, and analytical facilities. R. Moreno and T. Molina, from Instituto de Cerámica y Vidrio, CSIC, Madrid, are acknowledged by the realization of the agglomerate size measurements. 


\section{References}

[1] C. Bréchignac, P. Houdy, M. Lahmani (Eds.), Nanomaterials and Nanochemistry, Springer, Berlin, 2007.

[2] C. Dupas, P. Houdy, M. Lahmani (Eds.), Nanoscience: Nanotechnologies and Nanophysics, Springer, Berlin, 2007.

[3] C. Burda, X. Chen, R. Narayanan, M. El-Sayed, Chem. Rev. 105 (2005) 1025-1102.

[4] S. A. Edwards, The Nanotech Pioneers: Where are they taking us?. Wiley-VCH, Weinheim, 2006.

[5] G. A. Ozin, A. C. Arsenault, L. Cademartiri, Nanochemistry: A Chemical Approach to Nanomaterials. second ed, The Royal Society of Chemistry, Cambridge, 2009.

[6] M. T. Weller, C. S. Knee, J. Mater. Chem. 11 (2001) 701-712.

[7] C. N. R. Rao, A. Müller, A. K. Cheetham, (Eds.), Nanomaterials Chemistry, Wiley-VCH, Weinheim, 2007.

[8] D. Vollath, Nanomaterials: An Introduction to Synthesis, Properties and Applications, Wiley-VCH, Weinheim, 2008.

[9] B. L. Cushing, V. L. Kolesnichenko, C. J. O’Connor, Chem Rev. 104 (2004) 3893-3946.

[10] G. Garnweitner, L. M. Goldenberg, O. V. Sakhno, M. Antonietti, M. Niederberger, J. Stumpe, Small 3 (2007) 1626-1632; and references therein.

[11] H. Q. Wang, G. Yang, Q. Y. Li, X. X. Zhong, F. P. Wang, Z.-S. Li, Y. Li., New J. Chem. 35 (2011) $469-475$.

[12] R. Villanueva, A. Gómez, P. Burguete, E. Martínez, A. Beltrán, F. Sapiña, M. Vicent, E. Sánchez, J. Am. Ceram. Soc. 94 (2011) 236-243.

[13] Y. D. Tretyakov, N. N. Oleynikov, O. A. Shlyakhtin, Cryochemical Technology of Advanced Materials, Chapman \& Hall Ltd, London, 1997.

[14] G. Chen, W. Wang, Drying Technol. 25 (2007) 29-35.

[15] C. Tallón, R. Moreno, M. I. Nieto, Int. J. App.l Ceram. Technol. 6 (2009) 324-334.

[16] T.Boix, Z. El Fadli, F. Sapiña, E. Martínez, J.V. Folgado, A. Beltrán, Chem. Mater. 14 (2002) 688696.

[17] D. Vie, N. Valero, E. Martínez, F. Sapiña, J. V. Folgado, A. Beltrán, J. Mater. Chem. 12 (2002) 1017-1021. 
[18] S. Alconchel, F. Sapiña, E. Martínez, Dalton Trans. 2004 2463-2468.

[19] F. Cardarelli, Materials Handbook. $2^{\text {nd }}$ edition, Springer, London, 2008.

[20] C. Barry Carter, M. Grant Norton, Ceramic Materials: Science and Engineering, Springer, London, 2007.

[21] R. Raudaskoski, E. Turpeinen, R. Lenkkeri, E. Pongrácz, R. L. Keiski, Catalysis Today 144 (2009) 318-323.

[22] V. V. Plashnitsa, P. Elumalai, T. Kawaguchi, Y. Fujio, N. Miura, J. Phys. Chem. C 113 (2009) 78577862.

[23] A. Lashtabeg, S. J. Skinner, J Mater Chem 16 (2006) 3161-3170.

[24] C. Piconi, G. Maccauro, Biomaterials 20 (1999) 1-25.

[25] E.C. Subbarao, H.S. Maiti, K.K. Srivastava, Phys. Status Solidi A 24 (1974) 9-40.

[26] S. P. S. Badwal, Solid State Ionics 52 (1992) 23-32.

[27] J. B. Goodenough, Annu. Rev. Mater. Res. 33 (2003) 91-128.

[28] N. H. Menzler, F. Tietz, S. Uhlenbruck, H. P. Buchkremer, D. Stöver, J. Mater. Sci. 45 (2010) 3109_ 3135.

[29] X. Q. Cao, R. Vassen, D. Stoever, J. Eur. Ceram. Soc. 24 (2004) 1-10.

[30] D. R. Clarke, S. Phillpot, Mater Today 8 (2005) 22-29.

[31] A. D. H. Cavaleiro, T. Jeff, Nanostructured Coatings, Springer, London, 2006.

[32] S. C. Tjong, H.Chen, Mater. Sci. Eng. R 45 (2004) 1-88.

[33] J. Rodriguez-Carvajal, FullProf Program, Collected Abstracts of Powder Difraction Meeting, Tolousse, France, 1990, 127-128.

[34] A. K.West, Solid State Chemistry and its Applications, John Wiley and Sons, Chichester, 1984.

[36] S. Tsunekawa, S. Ito, Y. Kawazoe, J. T. Wang, Nano Lett. 3 (2003) 871-875.

[36] S. Manna, T. Ghoshal, A. K. Deb, S. K. De, J. Appl. Cryst. 43 (2010) 780-789.

[37] A. Navrotsky, Chem. Phys. Chem. 12 (2011) 2207-2215.

[38] R. C. Garvie, J. Phys. Chem. 69 (1965) 1238-1241.

[39] M. W. Pitcher, S. V. Ushakov, A. Navrotsky, B. F. Woodfield, G. Li, J. Boerio- Goates, and B.M. Tissue, J. Am. Ceram. Soc. 88 (2005) 160-167.

[40] T. S. Sheu, T. Y. Tien, I. W. Chen, J. Am. Ceram. Soc. 75(1992) 1108-1116. 
[41] H. Yang, J. Ouyang, X. Zhang, N. Wang, C. Du, J. Alloy Compd. 458(2008) 474-478.

[42] P. Bouvier and G. Lucazeau, J. Phys. Chem. Solids 61 (2000) 569-578.

[43] K. Witke, W. Österle, A. Skopp, M. Woydt, J Raman Spectrosc. 32 (2001) 1008-1014.

[44] H. Fujimori, M. Yashima, S. Sasaki, M. Kakihana, T. Mori, M. Tanaka, M. Yoshimura, Chem. Phys. Lett. 346 (2001) 217-223.

[45] P. Fornasiero, A. Speghini, R. Di Monte, M. Bettinelli, J. Kaspar, A. Bigotto, V. Sergo, M. Graziani, Chem Mater 16 (2004) 1938-1944.

[46] X. L. Jiang, C. B. Liu, F. Lin, J. Mater. Sci. Technol. 23 (2007) 449-456.

[47] R. Lima, B. Marple, J. Therm. Spray Technol. 16 (2007) 40-63.

[48] P. Fauchais, G. Montavon, G. Bertrand, J. Therm. Spray Technol. 19(2010) 56-80. 
Table 1. Selected microstructural data for $\mathrm{ZrO}_{2}$ and $\mathrm{Zr}_{0.94} \mathrm{~A}_{0.06} \mathrm{O}_{1.97}(\mathrm{~A}=\mathrm{Y}$ or $\mathrm{Sc}$ ). Grain (crystallite) size obtained from X-ray diffractograms $\left(\mathrm{d}_{\mathrm{DRX}}\right)$; particle size obtained from scanning electron microscopic images $\left(\mathrm{d}_{\mathrm{SEM}}\right)$; specific surface area calculated assuming non-aggregated particles with sizes obtained from SEM images $\left(S_{\text {calc }}\right)$; specific surface areas from BET measurements, $\left(S_{\text {exp }}\right)$. Values corresponding to samples prepared at $773,973,1173,1373$ and $1573 \mathrm{~K}$.

\begin{tabular}{|c|c|c|c|c|c|}
\hline & $773 \mathrm{~K}$ & $973 \mathrm{~K}$ & $1173 \mathrm{~K}$ & $1373 \mathrm{~K}$ & $1573 \mathrm{~K}$ \\
\hline \multicolumn{6}{|l|}{0.00} \\
\hline$d_{\text {DRX }}(n m)$ & 14 & 15 & 23 & 37 & 56 \\
\hline $\mathbf{d}_{\mathrm{SEM}}(\mathrm{nm})$ & 38 & 57 & 77 & 110 & 368 \\
\hline$S_{\text {calc }}\left(\mathrm{m}^{2} / \mathrm{g}\right)$ & 28 & 19 & 14 & 9.6 & 2.9 \\
\hline$S_{\exp }\left(m^{2} / g\right)$ & 18 & 16 & 11 & 5.1 & 1.7 \\
\hline \multicolumn{6}{|l|}{ Y; 0.06} \\
\hline$d_{\text {DRX }}(n m)$ & 11 & 12 & 20 & 38 & 61 \\
\hline $\mathbf{d}_{\mathrm{SEM}}(\mathrm{nm})$ & 19 & 26 & 61 & 99 & 200 \\
\hline $\mathbf{S}_{\text {calc }}\left(\mathrm{m}^{2} / \mathrm{g}\right)$ & 52 & 38 & 16 & 10 & 5.0 \\
\hline$S_{\exp }\left(\mathbf{m}^{2} / g\right)$ & 7.8 & 5.9 & 3.8 & 3.2 & 1.9 \\
\hline \multicolumn{6}{|l|}{ Sc; 0.06} \\
\hline$d_{\text {DRX }}(n m)$ & 11 & 11 & 15 & 24 & 41 \\
\hline $\mathbf{d}_{\text {SEM }}(\mathbf{n m})$ & 33 & 51 & 86 & 145 & 271 \\
\hline$S_{\text {calc }}\left(\mathrm{m}^{2} / \mathrm{g}\right)$ & 33 & 21 & 13 & 7.6 & 4.0 \\
\hline$S_{\exp }\left(m^{2} / g\right)$ & 24 & 17 & 12 & 4.5 & 1.6 \\
\hline
\end{tabular}


Table 2. Selected structural data from X-ray powder diffraction studies of $\mathrm{Zr}_{1-\mathrm{x}} \mathrm{Y}_{\mathrm{x}} \mathrm{O}_{2-\mathrm{x} / 2}$ samples prepared at $973 \mathrm{~K}$.

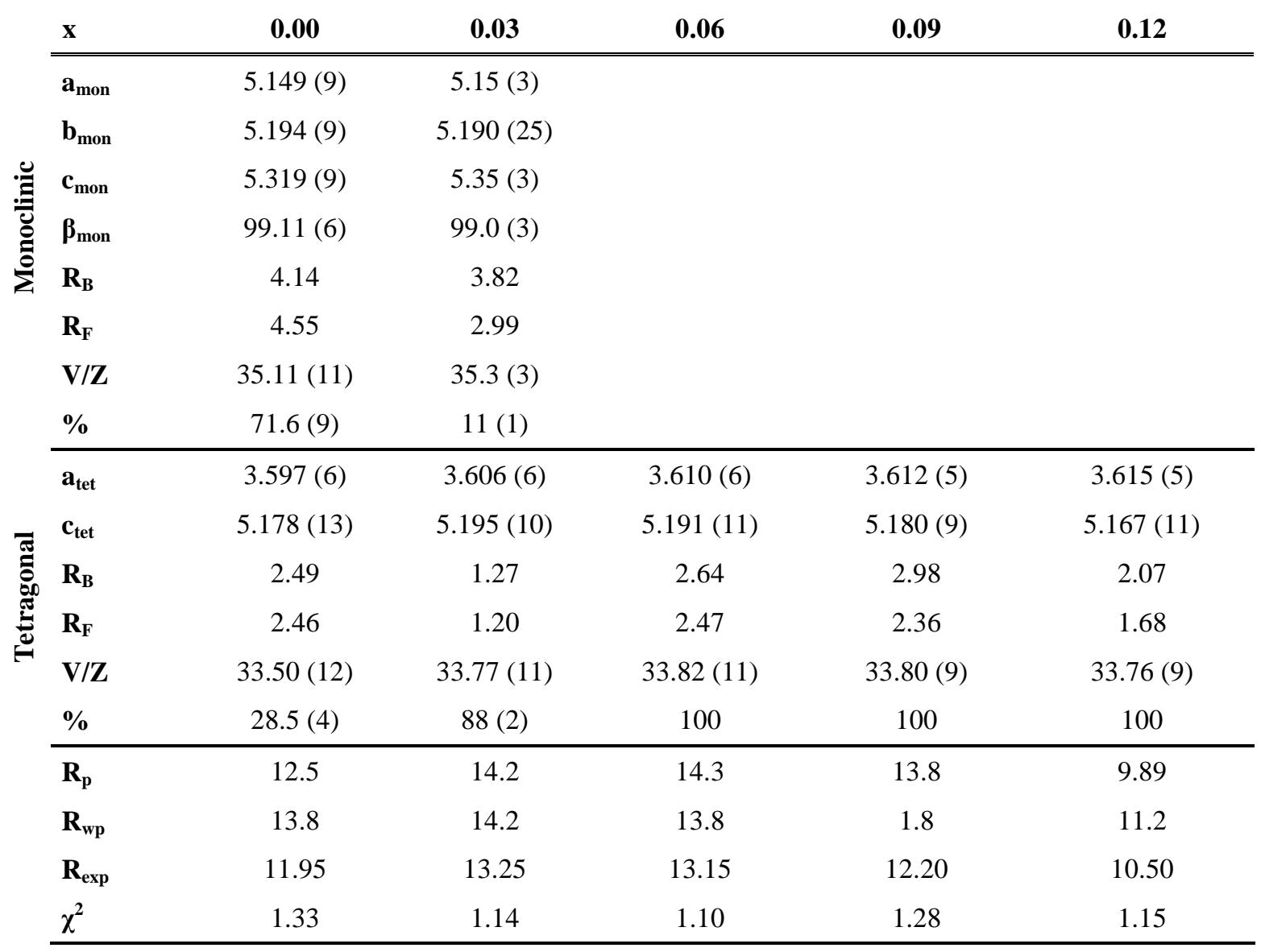


Table 3. Selected structural data from $\mathrm{X}$-ray powder diffraction studies of $\mathrm{Zr}_{1-\mathrm{x}} \mathrm{Y}_{\mathrm{x}} \mathrm{O}_{2-\mathrm{x} / 2}$ samples prepared at $1573 \mathrm{~K}$.

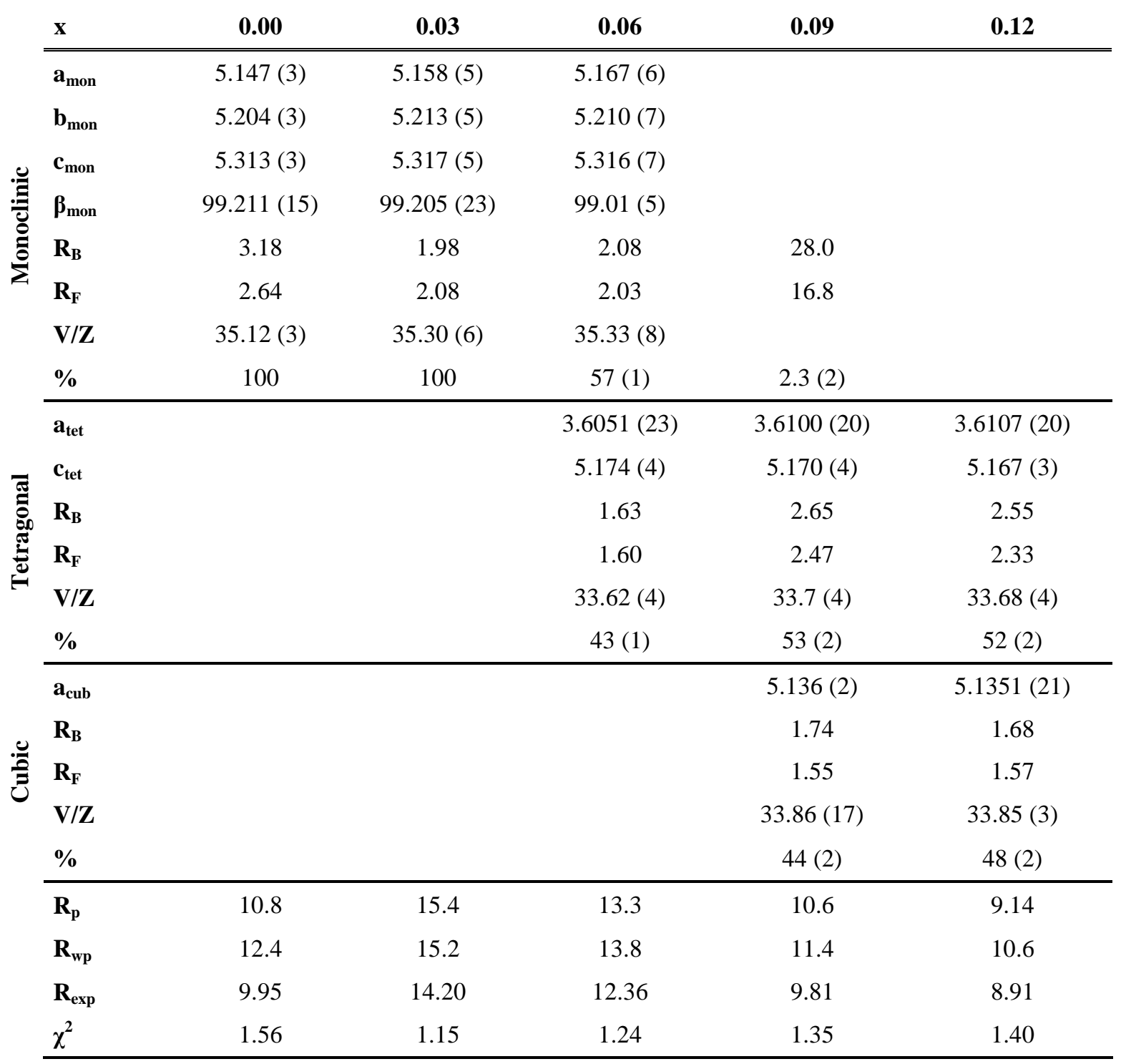


Table 4. Selected structural data from $\mathrm{X}$-ray powder diffraction studies of $\mathrm{Zr}_{1-\mathrm{x}} \mathrm{Sc}_{\mathrm{x}} \mathrm{O}_{2-\mathrm{x} / 2}$ samples prepared at $973 \mathrm{~K}$.

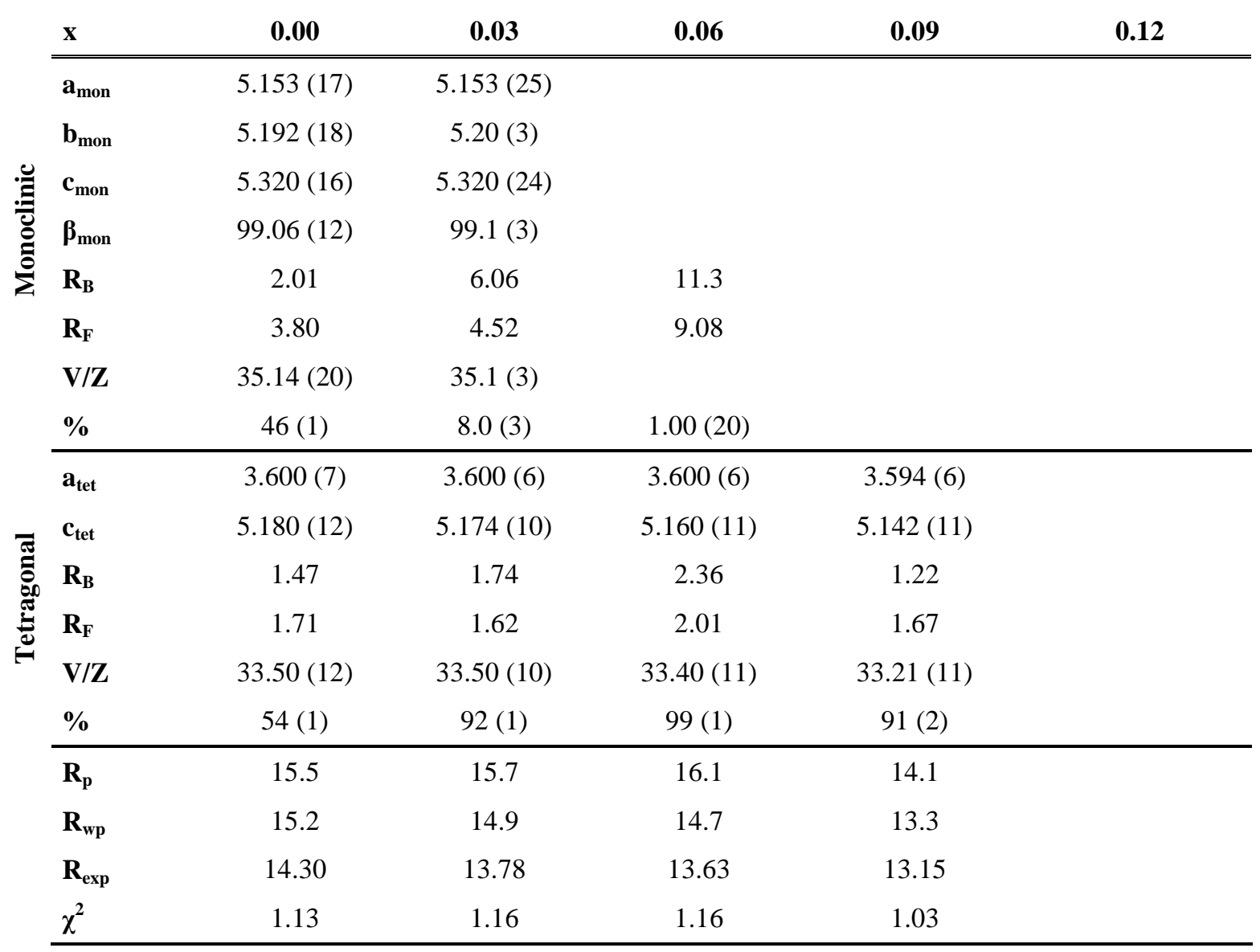


Table 5. Selected structural data from $X$-ray powder diffraction studies of $\mathrm{Zr}_{1-\mathrm{x}} \mathrm{Sc}_{\mathrm{x}} \mathrm{O}_{2-\mathrm{x} / 2}$ samples prepared at $1573 \mathrm{~K}$

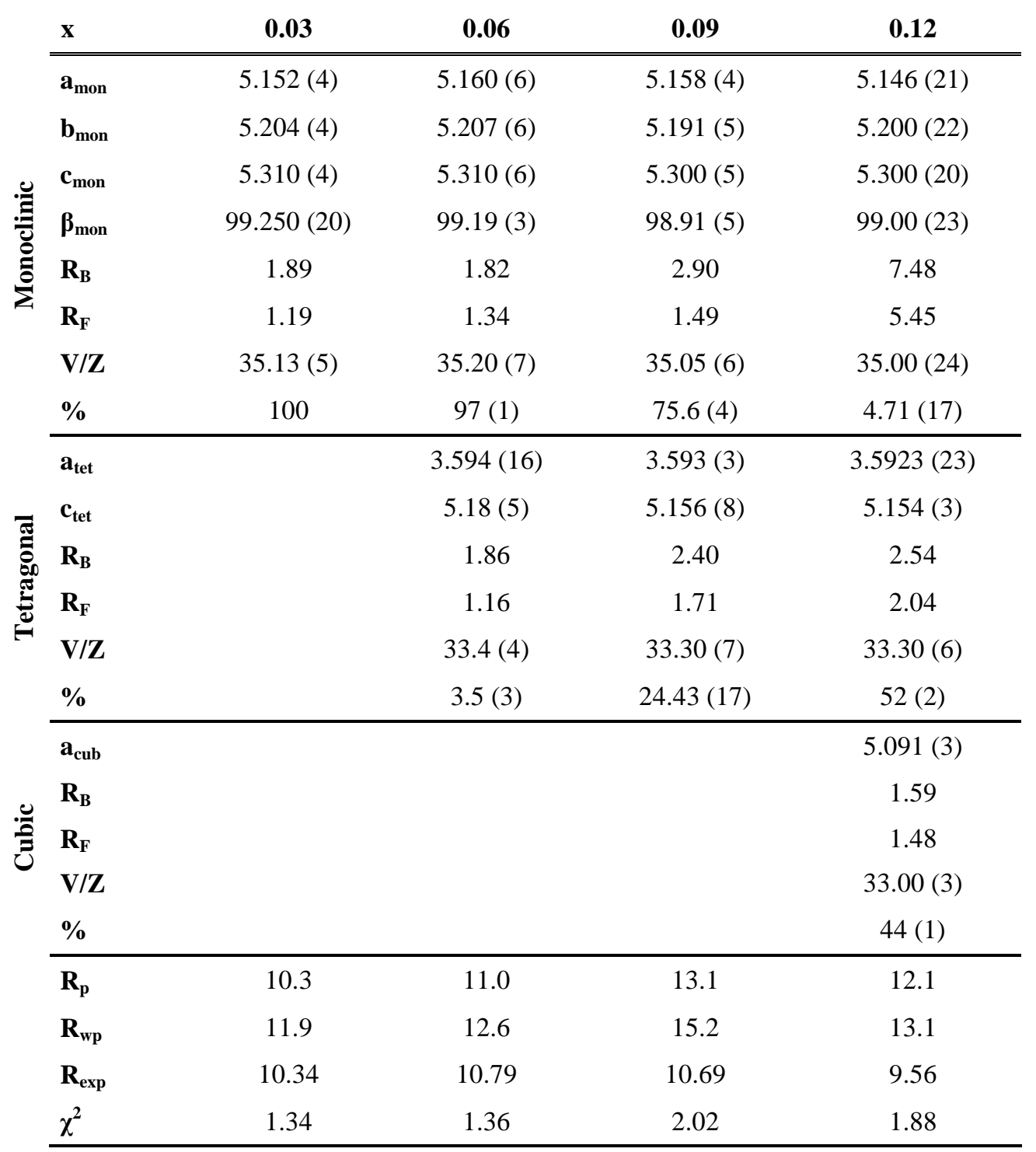




\section{Figure Captions}

Figure 1. X-ray diffraction patterns of materials prepared by thermal decomposition in oxygen of $(\mathrm{a}) \mathrm{x}=$ 0.00 , (b) $\mathrm{x}=0.06 \mathrm{Y}$, and (c) $\mathrm{x}=0.06 \mathrm{Sc}$ precursors. The temperatures of the thermal treatments are 673$1473 \mathrm{~K}$, in $200 \mathrm{~K}$ intervals, from bottom to top in all cases. Reflections marked with $\bullet$ are those corresponding to the tetragonal phase; those marked with $\circ$ correspond to monoclinic phase.

Figure 2. Scanning electron microscopic (SEM) images showing the microstructure of zirconia and Y and Sc doped zirconia. (a) $\mathrm{x}=0.00,973 \mathrm{~K}$; (b) $\mathrm{x}=0.06(\mathrm{Y}), 1173 \mathrm{~K}$; (c) $\mathrm{x}=0.06$ (Sc), $1373 \mathrm{~K}$; (d) $\mathrm{x}=$ 0.00, $1573 \mathrm{~K}$. Scale bars correspond to $300,300,400 \mathrm{~nm}$ and $1 \mu \mathrm{m}$, respectively.

Figure 3. Evolution of the monoclinic phase content, estimated from the integrated intensities of $(101)_{t}$ and $(-111)_{\mathrm{m}}$ peaks, for (a) $\mathrm{Y}$ and (b) Sc doped zirconias. For both series: $\mathbf{a}, \mathrm{x}=0.00 ; \bullet, \mathrm{x}=0.03 ; \boldsymbol{\Delta}, \mathrm{x}=$ $0.06 ; \circ, \mathrm{x}=0.09 ; \mathrm{X}, \mathrm{x}=0.12$.

Figure 4. Observed (dotted) and calculated (solid) X-ray diffraction profiles for $\mathrm{Zr}_{0.88} \mathrm{Y}_{0.12} \mathrm{O}_{0.94}$ prepared at $1573 \mathrm{~K}$. Tic marks below the diffractograms represent the allowed Bragg reflections. The residuals lines are located at the bottom of the figures. Main figure: refinement considering the presence of a tetragonal and a cubic phase, the whole pattern is displayed (20-110 $2 \Theta$ interval). Insert a) Refinement considering a tetragonal phase, in the $25-55^{\circ} 2 \theta$ interval: the residuals are indicative of a problem with the structural model. Insert b) Refinement considering the presence of a tetragonal and a cubic phase, in the $72-76^{\circ} 2 \theta$ interval: the multiplet centred at ca. $74^{\circ} 2 \theta$ is satisfactorily interpreted with this structural model. Insert c) Refinement considering the presence of a tetragonal and a cubic phase, in the $20-55^{\circ} 2 \theta$ interval.

Figure 5. Raman spectra of $\mathrm{Zr}_{0.88} \mathrm{Y}_{0.12} \mathrm{O}_{0.94}$ prepared at 973 and $1573 \mathrm{~K}$. a) Uncorrected Raman spectra, $200-800 \mathrm{~cm}^{-1}$ region. b) Baseline corrected spectrum of sample prepared at $973 \mathrm{~K}$ (thick line) in the 500$750 \mathrm{~cm}^{-1}$ region, and band decomposition (thin lines, different components; dashed line, sum of components). c) Baseline corrected spectrum of sample prepared at $1573 \mathrm{~K}$ (thick line) in the 500-750 $\mathrm{cm}^{-1}$ region, and band decomposition (thin lines, different components; dashed line, sum of components). Bands 1 are assigned to the cubic phase, 2 and 3 to the tetragonal phase, and 4 to a defect induced band (see text). 


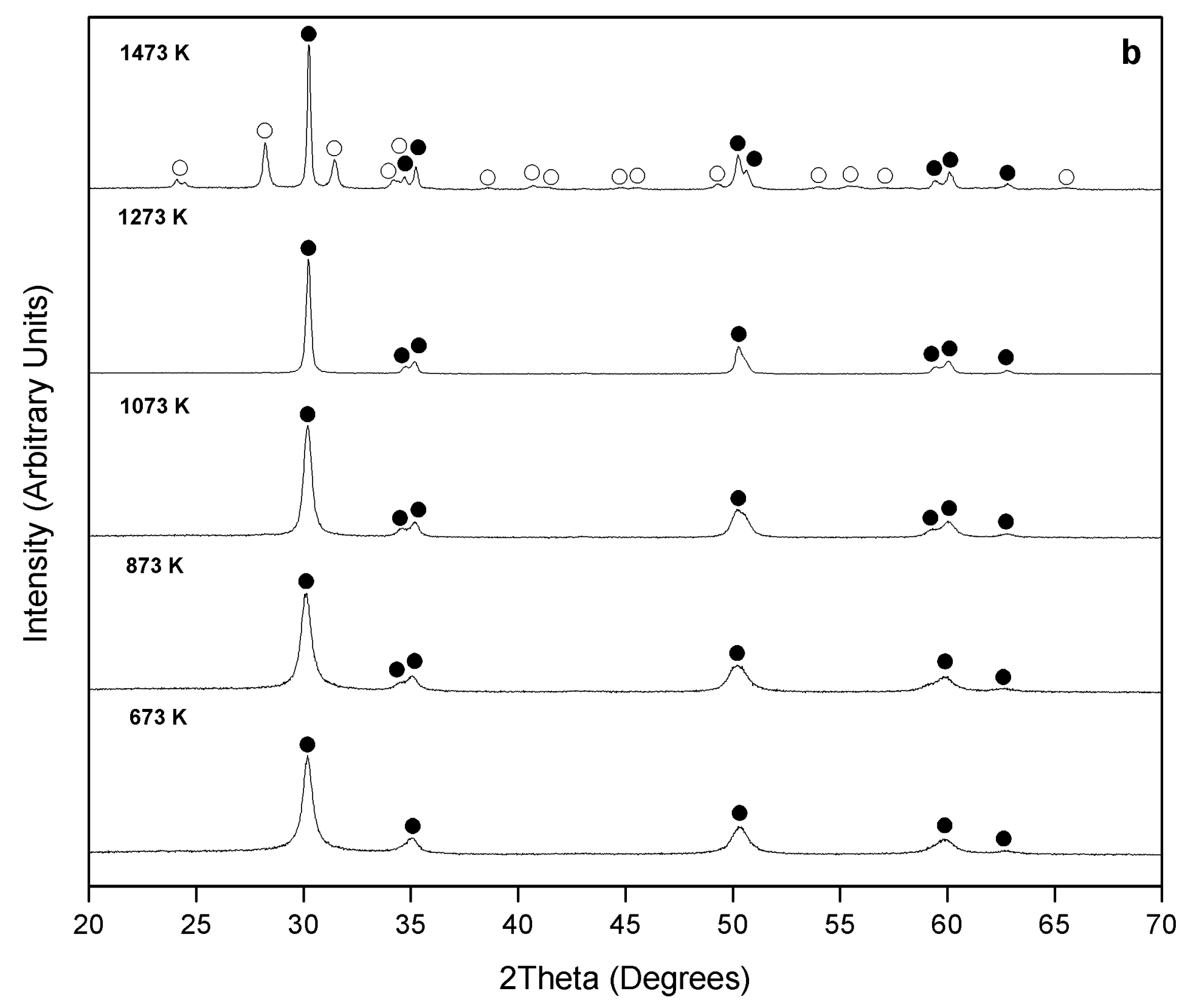




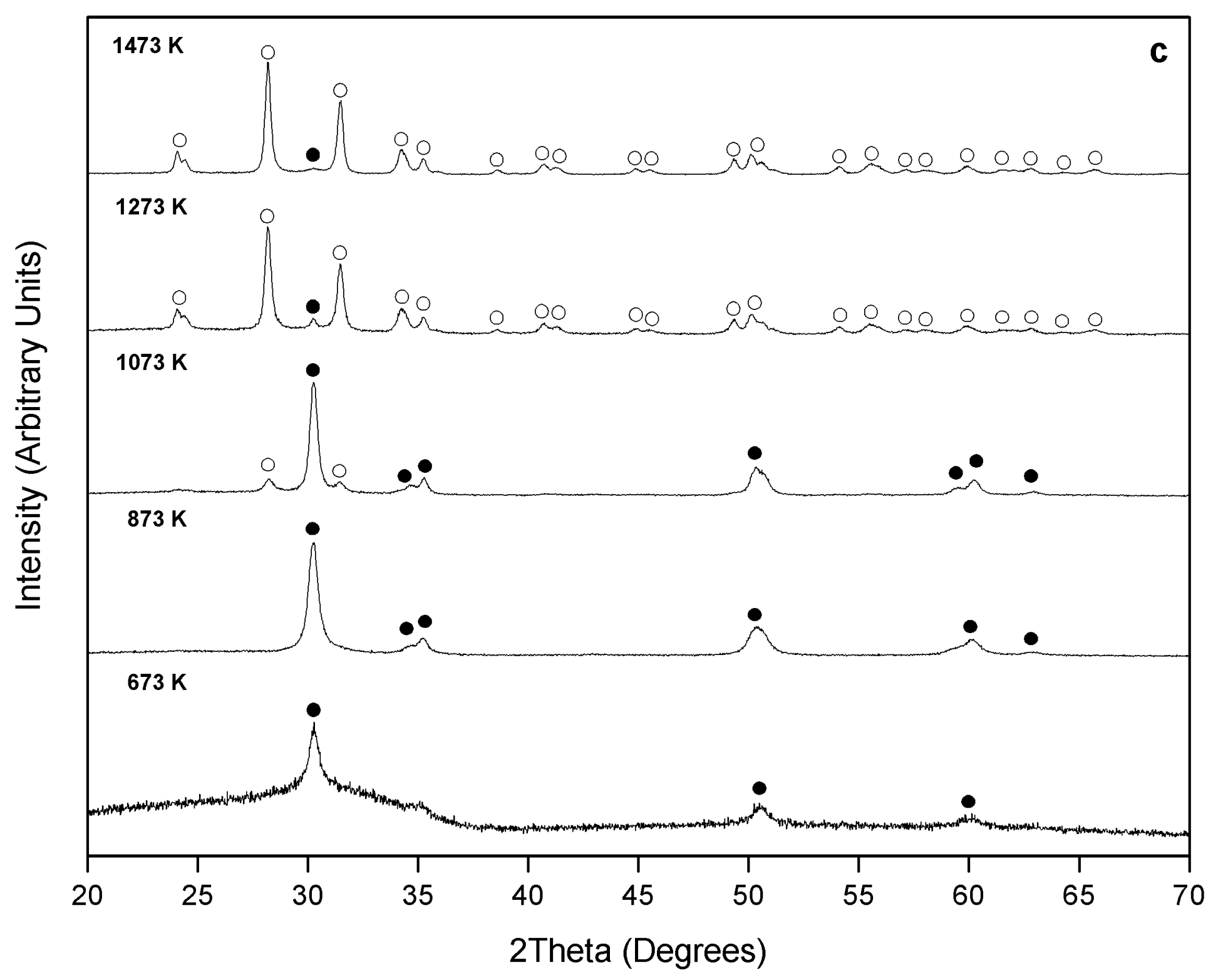




\section{a}

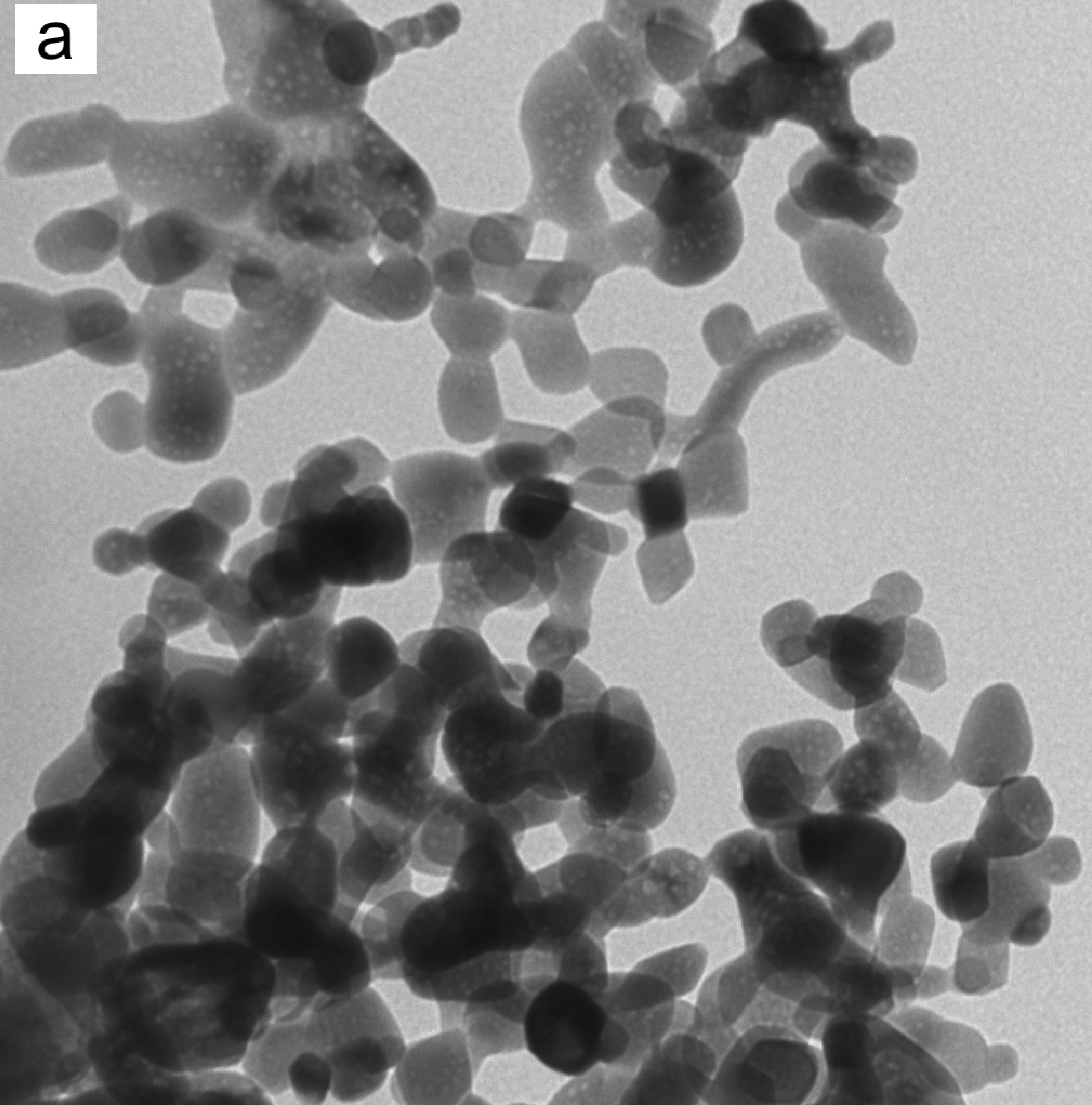

- 


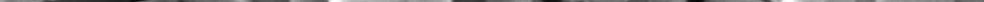




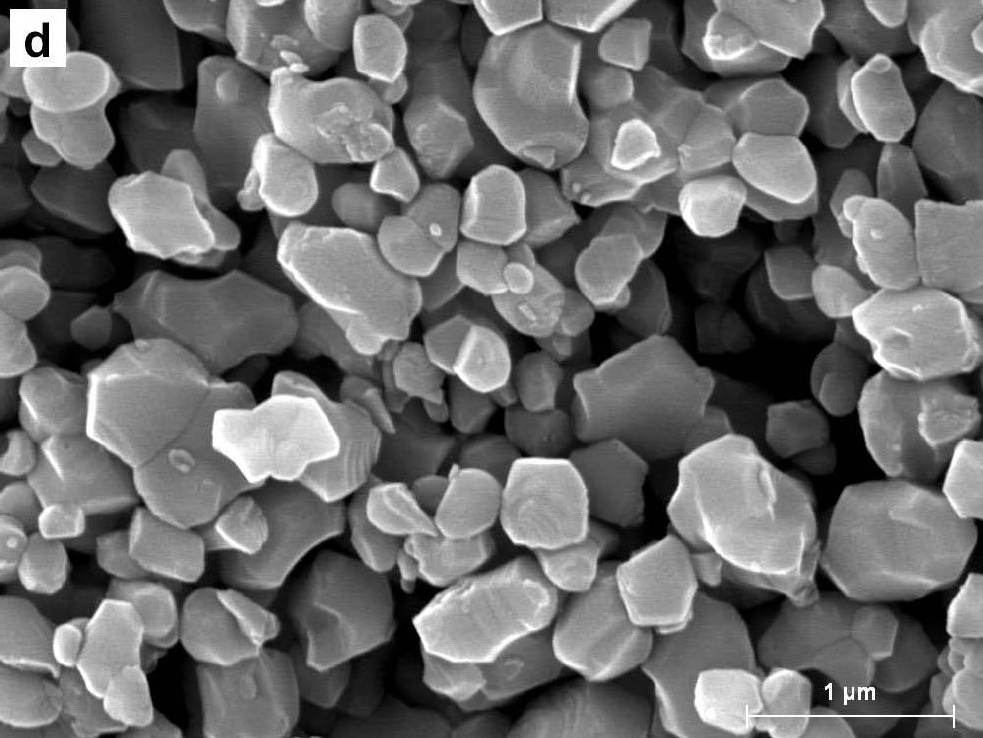




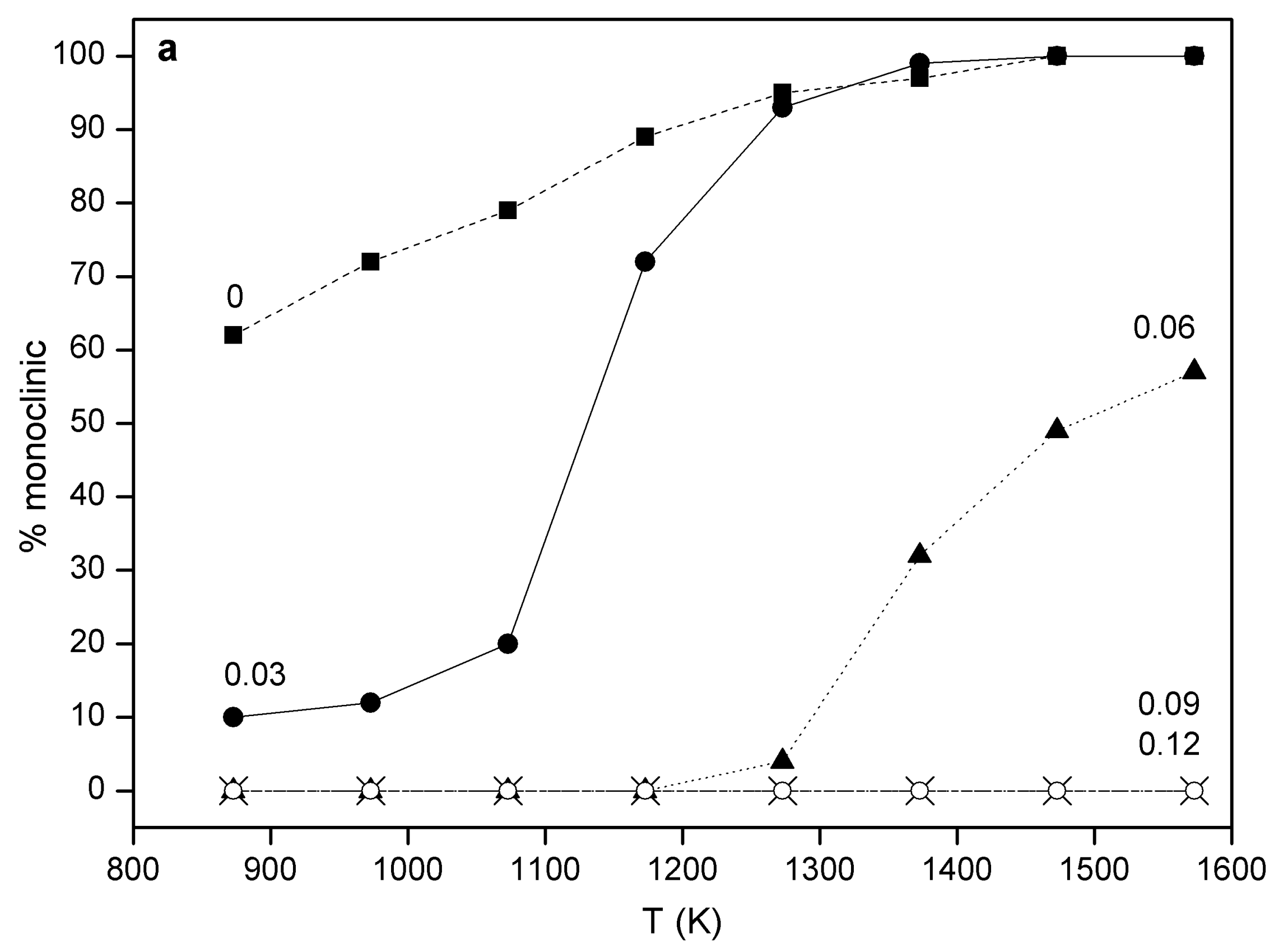




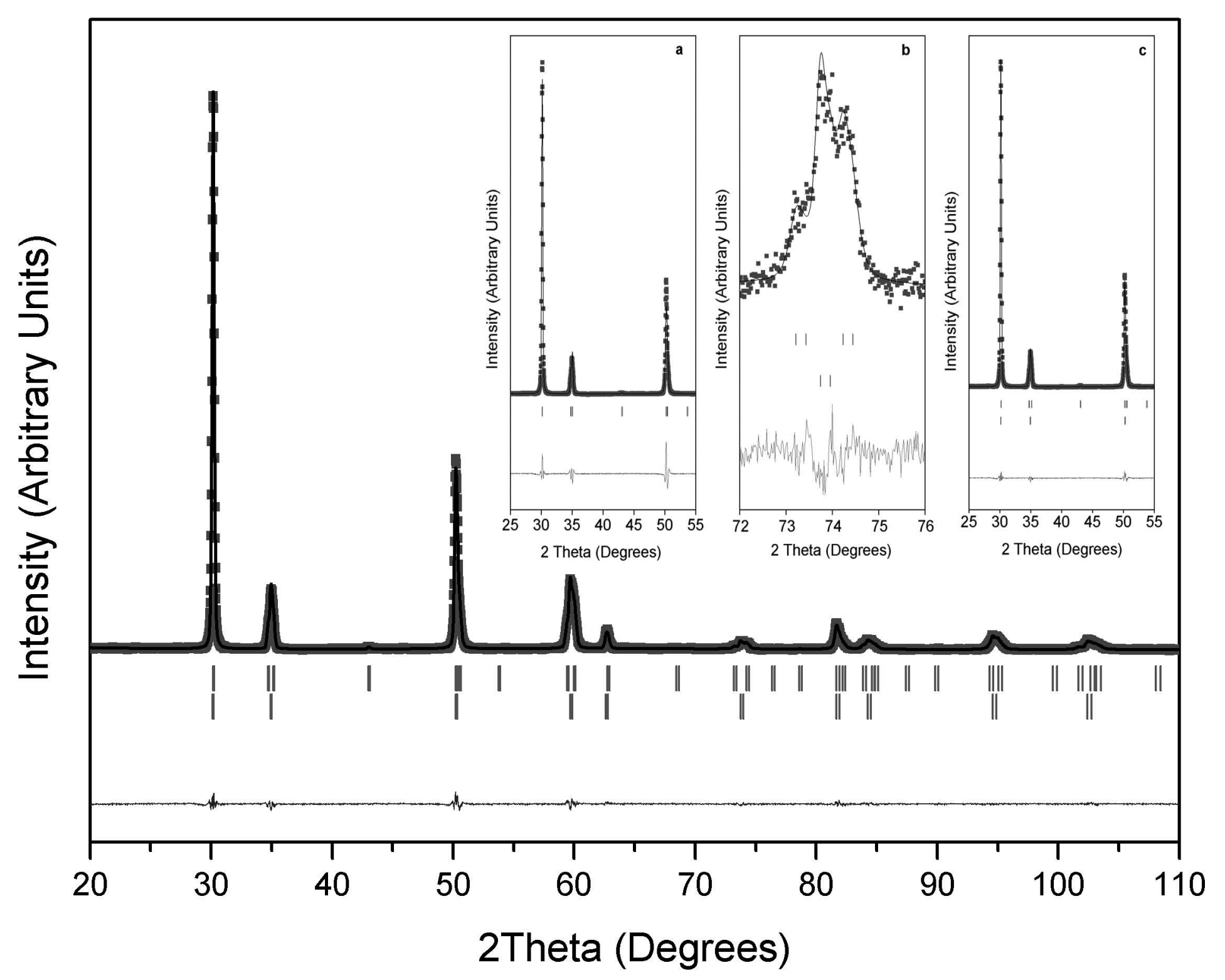




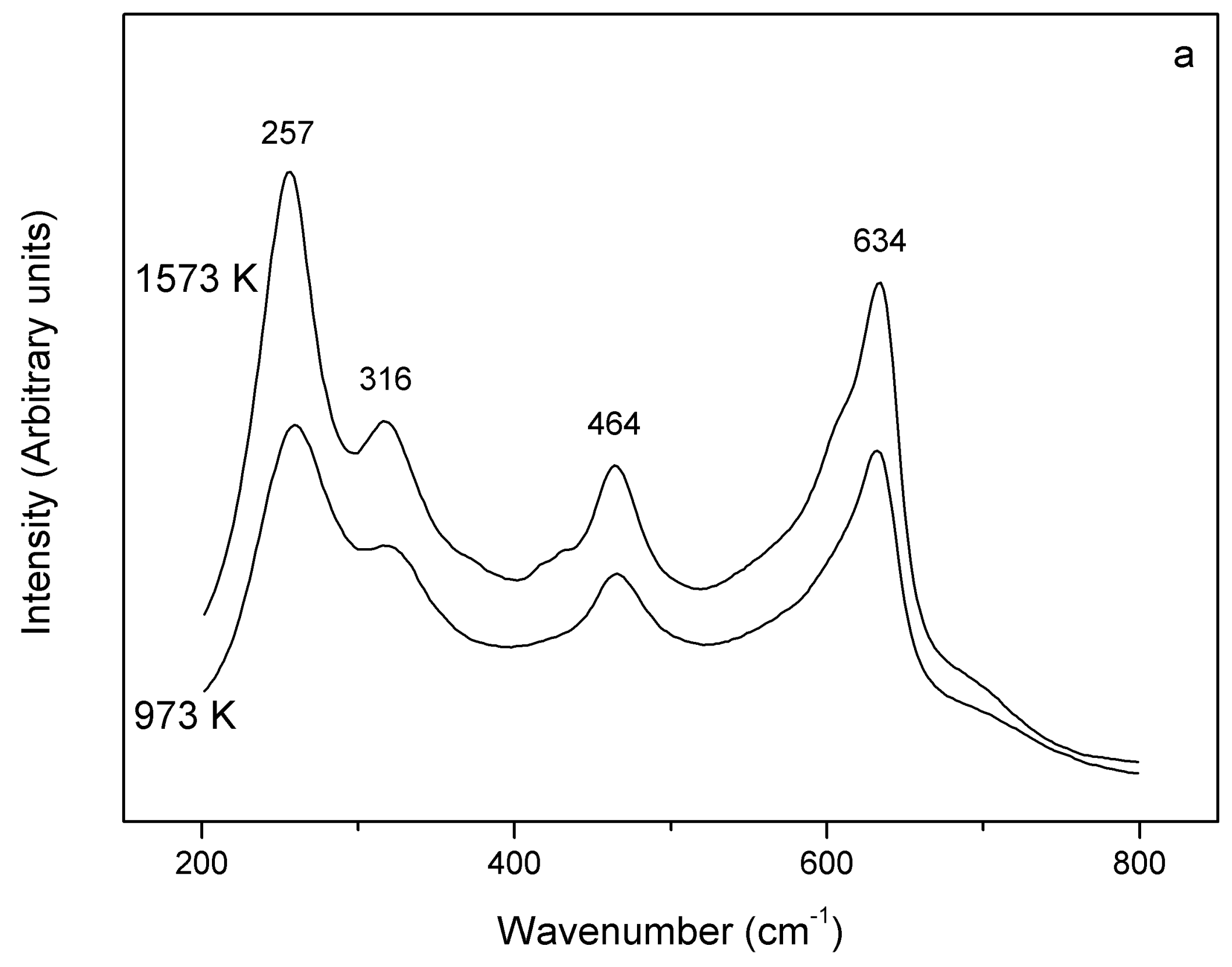




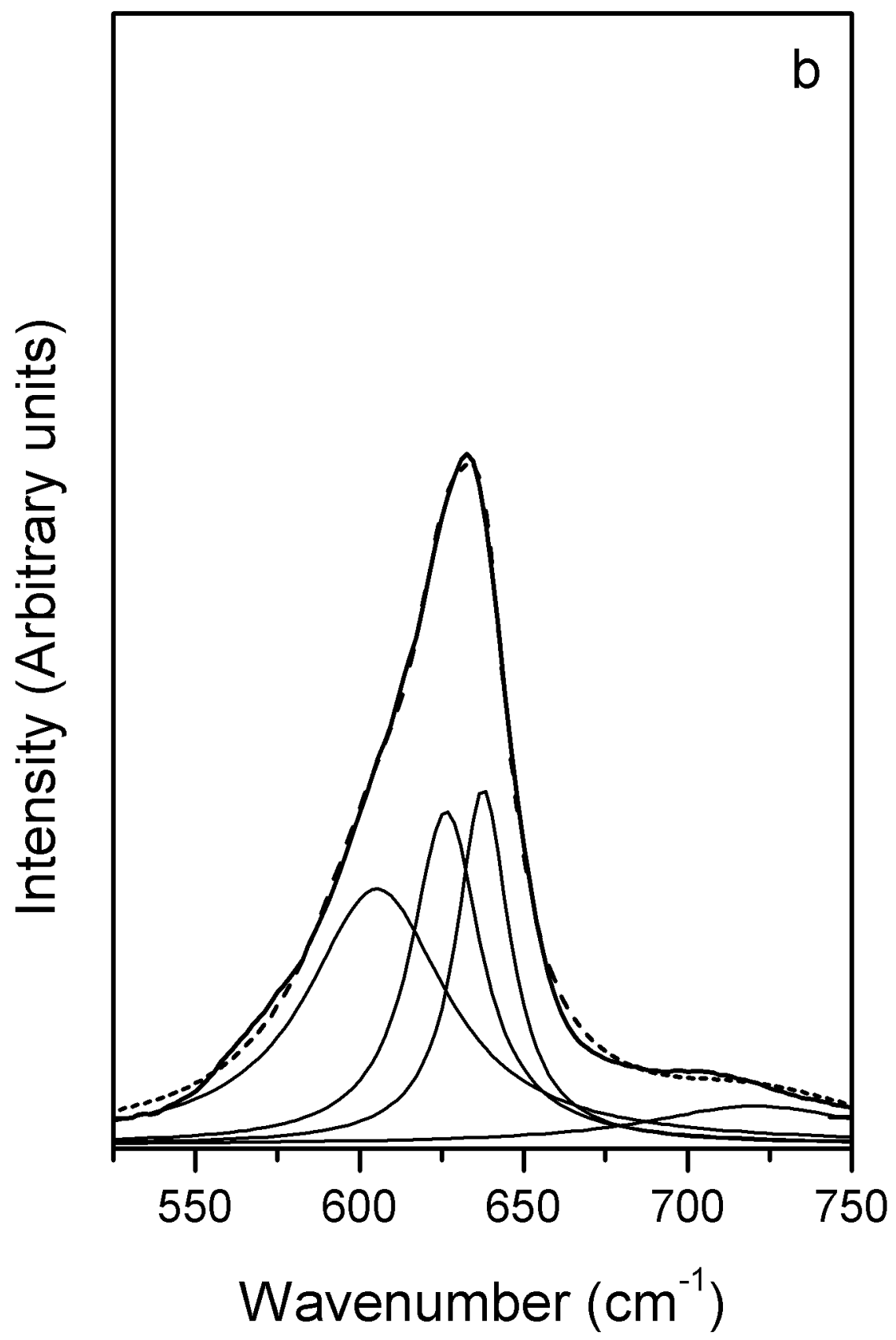




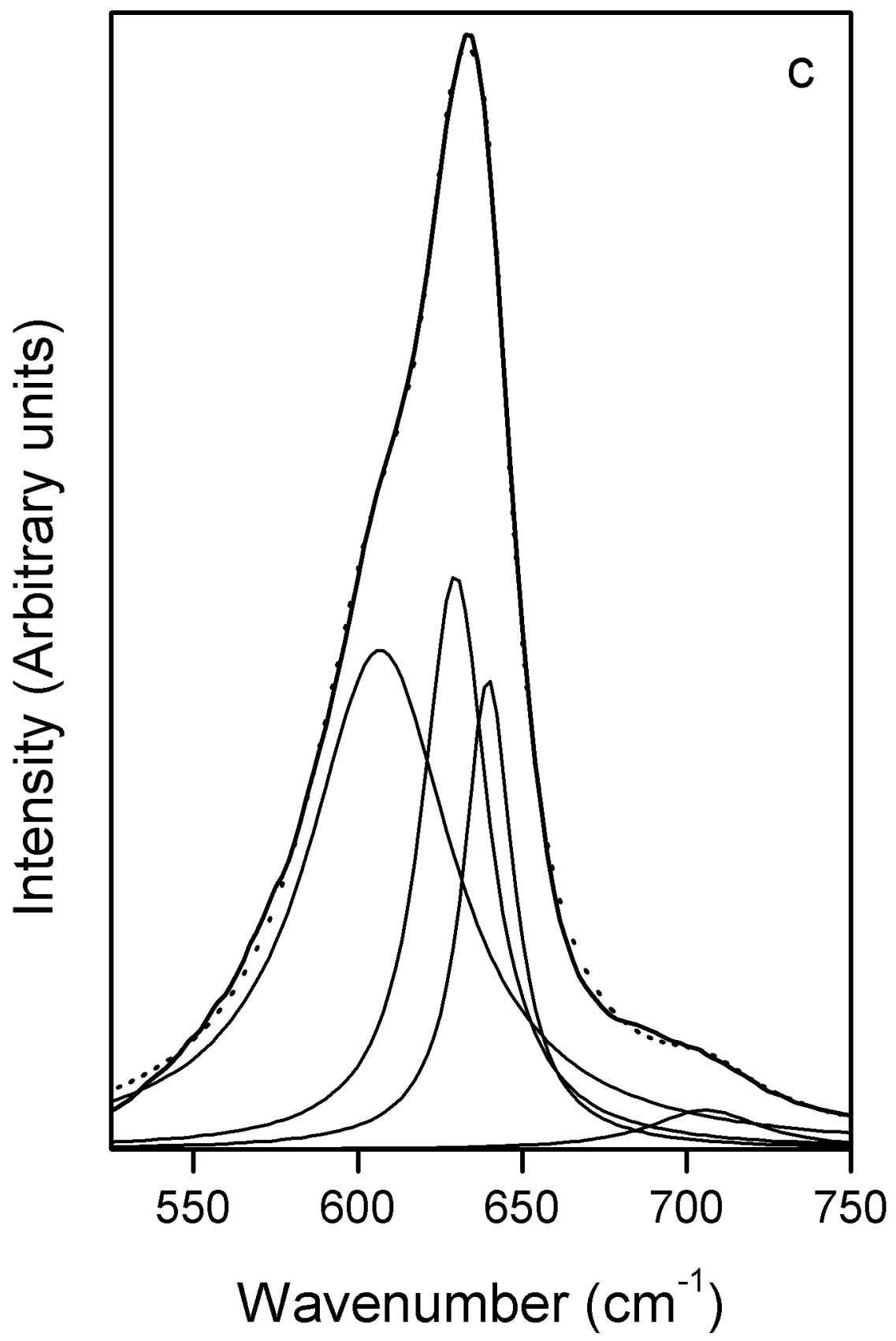

